\title{
PERMEABILITY AND PROPERTIES OF THE MEMBRANES SURROUNDING THE DEVELOP- ING EGG OF HOMARUS VULGARIS
}

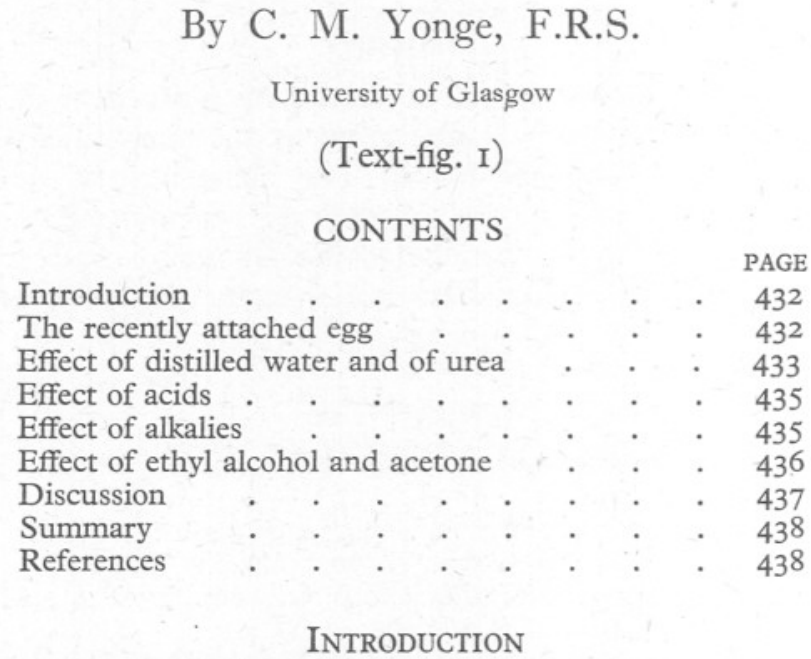

The non-protoplasmic membranes surrounding the developing eggs of Homarus vulgaris M.-Edw. and other decapod Crustacea have been shown (Yonge, 1937) to consist of an inner chitinous membrane secreted by the oviducal epithelium and an outer one of cuticle (protein, probably with adsorbed lipin) formed by the cement (tegumental) glands in the pleopods of the female. They thus correspond in nature and origin to the two constituents of the integument (Yonge, 1932). In the present paper an account is given of experiments on the permeability of these membranes. The results provide further evidence of the presence and distinct properties of the two membranes, and also show that they have similar properties of permeability to those demonstrated for the cuticular and chitinous layers of the integument (Yonge, I936).

\section{The Recently Attached EgG}

The experiments were carried out on eggs taken from the abdomen of a berried female which had recently spawned. The eggs were therefore still spherical and development had barely begun, so that the contents consisted almost exclusively of yolk. This possesses a dark green pigment, and the change in colour of this to red which occurs when certain substances penetrate the surrounding membranes is a useful initial indication of their entry. The inner, chitinous membrane is closely applied to the protoplasmic membrane, formed 
in the ovary, which surrounds the egg. The outer, cuticular membrane does not lie so close to the inner membrane. This is due to its different mode of formation. The secretion of the cement glands flows round the eggs when they pass back from the genital openings to the under side of the abdomen during the process of egg laying. This flowing round is possible owing to the low surface tension of the cuticle (Yonge, I932). A 'funiculus' of twisted strands of the cement attaches the eggs to the egg-carrying setae on the pleopods. The appearance of such a recently attached egg is indicated in Fig. I $a$.

In the experiments described below detached eggs were placed in small glass dishes and the effect upon them of various fluids was followed, with the aid of a low-power binocular microscope, for appropriate periods. Controls left in sea water for the same periods showed no change.

\section{EFFECT OF Distilled WATER AND OF UREA}

In distilled water the eggs remained green but quickly swelled, increasing in diameter by up to $30 \%$ at the end of $4 \mathrm{hr}$. (Fig. I b). After $24 \mathrm{hr}$. the swelling had decreased, to not more than ro \% above the initial diameter. These changes are due to changes in size of the egg contents as shown in Fig. I $b$, the inner and outer membranes stretching and the space between them being obliterated. The outer membrane, it will be noted, stretched initially and then shrank, i.e. it must possess considerable elasticity. The inner membrane ruptured although this was difficult to see owing to the tightness with which it was forced against the intact outer membrane, but occasionally, as shown in Fig. I $b$, a distinct irregularity of the surface was noted which can only have been the result of rupture. When the stretched outer membrane was punctured with a fine needle the whole burst with some force indicating considerable internal pressure.

The effect of exposure to molar solutions of urea was very similar. Swelling was slower, the diameter increasing by 10 \% at the end of $24 \mathrm{hr}$. Subsequently this sometimes increased further. The inner membrane was observed to rupture in several cases.

The results of these experiments are explicable on the assumption that the outer and inner membranes have the same properties of permeability as those demonstrated for the cuticle and chitin respectively (Yonge, 1936), namely restricted, almost semi-permeability for the former and free diffusion for the latter. With the destruction of the egg and its protoplasmic membrane, high internal osmotic pressure would cause inward passage of water through the largely semi-permeable outer membrane. Consequent swelling of the egg mass would explain the rupture of the inner membrane but the elasticity of the outer membrane prevented this from bursting. The later shrinkage may have been due to some outward passage of solutes through this membrane, or possibly to coagulation of the egg mass and so reduction in osmotic pressure. 


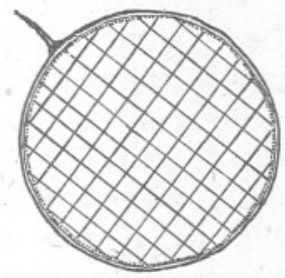

A

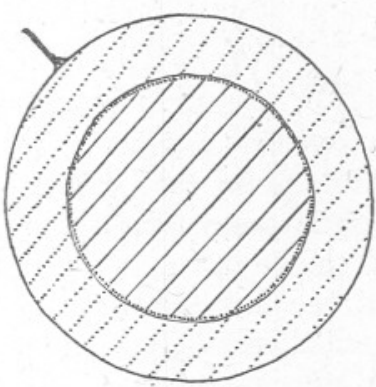

D

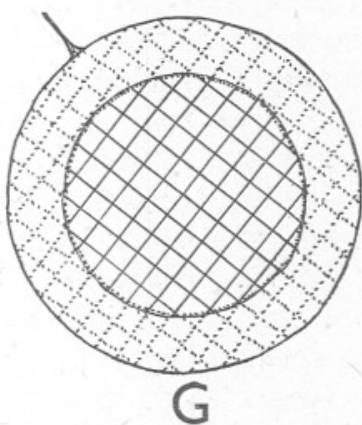

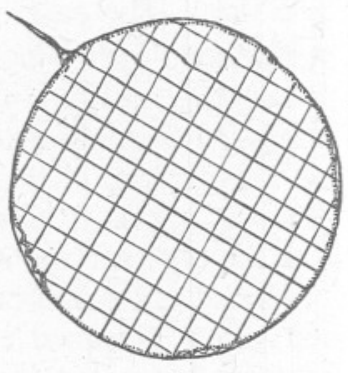

B

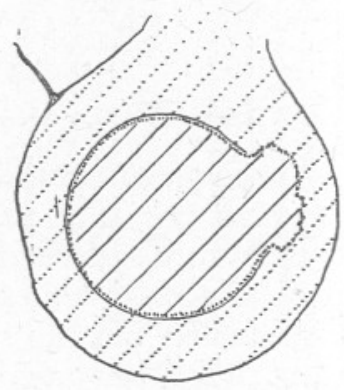

$E$

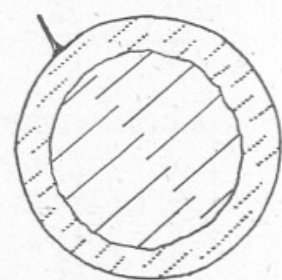

$\mathrm{H}$

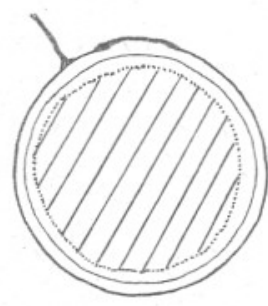

$C$
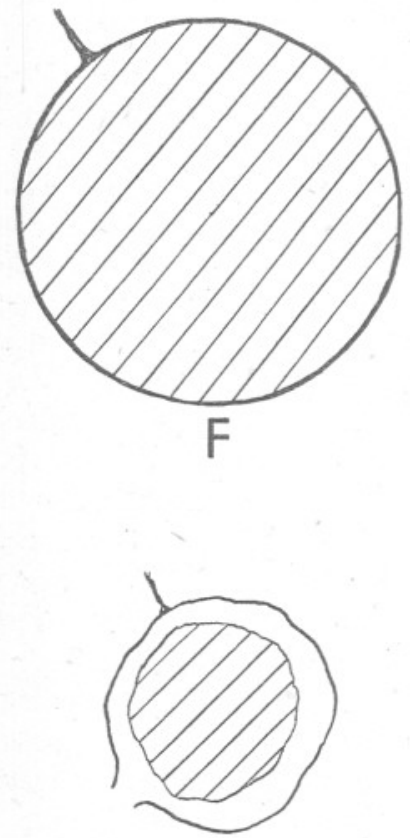

I

Fig. I. Egg of Homarus vulgaris after varying treatment. $\times$ I2. Crossed lines indicate green colour in egg mass, oblique lines red, incomplete oblique lines yellow. Similar dotted lines indicate dissolved pigment between membranes. Outer membrane (with attached "funiculus") shown somewhat thicker than inner membrane: limit of egg mass indicated where necessary by dotted line. $a$, normal (and control) egg; $b$, after $4 \mathrm{hr}$. in distilled water; c, after $24 \mathrm{hr}$. in $N$ hydrochloric acid; $d$, after $4 \mathrm{hr}$. in $N$ formic acid; $e$, final appearance after exposure to $N$ formic acid, both membranes ruptured; $f$, after $4 \mathrm{hr}$. in $N$ potassium hydroxide, prior to disintegration of outer membrane; $g$, after $6 \mathrm{hr}$. in $N$ ammonia with inner membrane intact; $h$, after $24 \mathrm{hr}$. in absolute ethyl alcohol; $i$, after $24 \mathrm{hr}$. in acetone. 


\section{EFFECT OF ACIDS}

The eggs were immersed in normal solutions of two strong mineral acids, hydrochloric and nitric, and the two low fatty acids, formic and acetic. Both mineral acids penetrated rapidly. The eggs began to turn red after I2-I5 min. and were red throughout within $30 \mathrm{~min}$. The contents were at the same time coagulated and shrank away from the inner membrane which in turn receded somewhat from the outer membrane (Fig. I $c$ ). The absence of internal pressure was revealed when the two membranes, well separated from one another, were successively punctured. The eggs remained indefinitely in the condition described.

Judging from the speed with which the eggs changed colour, the fatty acids penetrated somewhat more slowly. But since these acids certainly penetrate cuticle quicker than do mineral acids (Yonge, I936) and the outer membrane has in all other respects identical properties with the cuticle, the slower change in colour is probably due to the weaker and less toxic nature of the acids, not to their slower penetration. Swelling occurred more rapidly with formic acid (known to penetrate the cuticle quicker than acetic (Yonge, 1936)). An increase in diameter of about $50 \%$ was observed within $4 \mathrm{hr}$. This swelling, as shown in Fig. I $d$, was due to an increase in the space between the two membranes which filled with a reddish fluid revealing diffusion of dissolved material through the inner membrane. The dissolved pigment never passed through the outer membrane. The high internal pressure was again demonstrated by puncturing the outer membrane. The inner membrane usually burst, sometimes after about $3 \mathrm{hr}$. with formic acid (Fig I $e$ ). It always retained its original diameter, as indicated in Fig. I $d$, until it burst, revealing its rigid character. The outer membrane subsequently frequently also burst (Fig. I $e$ ) and the egg mass finally disintegrated.

Dissolution of the fatty constituents of the yolk in the fatty acids and consequent swelling will explain the bursting of the inner membrane and the high osmotic pressure the stretching and eventual bursting of the outer membrane. The passage of red pigment into the space between the two membranes, but not through the outer membrane, reveals the different properties of the two membranes.

\section{EFFECT OF AlKalies}

Eggs were exposed to normal solutions of potassium and sodium hydroxides and of ammonia. It had previously been found (Yonge, I936) that the special properties of permeability possessed by the cuticle are destroyed by exposure to normal potassium or sodium hydroxide. Uncalcified integument so treated possesses the free permeability of chitin. Both strong alkalies penetrated rapidly through the egg membranes causing a change in colour in $5 \mathrm{~min}$. with potassium, and Io min. with sodium hydroxide. Swelling followed almost immediately, the diameter increasing by about $50 \%$ after $4 \mathrm{hr}$. The inner 
membrane soon burst and permitted the egg mass to fill the entire space within the outer membrane (Fig. If), i.e. as with fatty acids. But the substance of this membrane was attacked, it became swollen and soft and finally disintegrated, unlike that of the inner membrane which persisted. When punctured while still intact (but after dístension had occurred) there was no evidence of internal pressure and no change in shape. The egg mass finally disintegrated.

The explanation of these results would appear to be that the egg contents were dissolved by the strong alkalies, their swelling caused rupture of the inner membrane and the high osmotic pressure distension of the outer membrane. The substance of this membrane was affected, after initial distension had occurred, by these alkalies and its special properties of permeability lost, exactly as had previously been demonstrated for the cuticle (Yonge, 1936). The dissolution of the outer and persistence of the inner membrane indicates that only the latter is chitinous.

Ammonia had much the same effect as fatty acids but there was no change in colour, a greenish fluid diffusing outward through the inner, but never the outer, membrane. Stretching of the outer membrane began after about I hr., the diameter increasing up to $40 \%$ (Fig. I $g$ ). Puncturing revealed high internal pressure. The inner membrane frequently ruptured (not shown in Fig. I $g$ ) but the outer membrane never did so. Elasticity of this was revealed by a decrease, usually within $24 \mathrm{hr}$., to about $20 \%$ above the initial diameter. This weak alkali had no effect on the substance of the outer membrane and its effects are those of a fat solvent, like those of the fatty acids, precisely as found in experiments on the cuticle (Yonge, 1936).

\section{EfFect of Ethyl Alcohol and Acetone}

Alcohol penetrates rapidly and eggs began to turn red within $5 \mathrm{~min}$. but later turned yellow and this colour extended into the area between the membranes. An initial reduction in diameter of up to $17 \%$ at the end of $4 \mathrm{hr}$. was followed by expansion to slightly over the original diameter. The substance of the egg mass coagulated and shrank with the inner membrane adhering to it so that the two membranes became widely separated (Fig. I $h$ ). Acetone, judging by the rate of colour change, penetrated more slowly; complete change in colour took about $4 \mathrm{hr}$. There was a marked irregular shrinkage of the outer membrane leading to rupture although it remained in situ (Fig. I $i$ ). The inner membrane was similarly shrivelled and both became very hard. There was no outward flow of pigment through the inner membrane.

Uncalcified integument, with or without cuticle, when treated in air with alcohol or acetone becomes impermeable owing to dehydration (Yonge, 1936). There is apparently sufficient water within the outer membrane to prevent this effect with alcohol but not with acetone. In the former pigment diffuses out through the inner (but, as always, not through the outer) membrane, while the outer membrane stretches when the internal osmotic pressure is raised 
owing to the dissolution of some constituents of the egg mass. With acetone both membranes are apparently dehydrated, and so become shrunken and impermeable.

\section{Discussion}

The presence of two non-living membranes around the developing eggs is clearly demonstrated. They frequently separate widely from one another while the egg mass may also separate from the inner one, as after treatment with mineral acids (Fig. I c). The absence of any appreciable development in the egg disposes of the suggestion that the inner one may be a larval integument while this has already been shown to be present when the egg leaves the oviduct where it is formed (Yonge, 1937). The different behaviour of the two membranes is explicable on the assumption that the outer has the restricted permeability already demonstrated for cuticle while the inner has the free diffusion of chitin. The former distends when high osmotic pressure is generated within it, the latter allows pigment and other dissolved material to diffuse through it. It frequently bursts owing to swelling of the egg mass but in ammonia, for instance, it never bursts although the outer membrane may distend to $40 \%$ above its initial diameter owing to the passage of dissolved material through the inner membrane and consequent rise in osmotic pressure. The irreversible action of strong alkalies on the outer membrane is identical with their action on the cuticle of the integument.

The cuticle is known to be harder than chitin (Yonge, I936), but a new point which emerges from these experiments is the extent to which the outer membrane can stretch and also its elasticity. Shrinkage frequently followed initial distension. This elasticity is therefore probably a property of the cuticular constituent of the integument also. In the case of the eggs this has biological significance. The outer membrane attaches the eggs to the pleopods in the decapod Crustacea, but it also protects them and has to withstand the pressure of adjacent eggs and the effect of the constant beating of the pleopods needed to produce the respiratory current around the developing mass of eggs. In this connection its elasticity as well as its firm consistency will be of real value. Moreover during development the egg increases in size, becoming oval with the long axis $50 \%$ greater than the original diameter. The inner membrane appears to be ruptured and absorbed, its place being effectively taken by a series of larval integuments. But the outer membrane remains intact until hatching which, as already suggested for other Crustacea (see Yonge (I937) for references), may possibly involve its rupture by osmotic pressure. Certainly the outer membrane could not remain around the developing egg, securing it to the pleopods and protecting it, were it not capable of stretching greatly.

With Crustacea which liberate their eggs freely into the sea, such as the Penaeidea and the Euphausiacea, the problem of pressure has not to be overcome but expansion during development remains. We have no exact knowledge about the membranes surrounding the eggs in these animals; but Bargmann 
(1937) has shown that in Euphausia superba Dana the oviduct is surrounded by a mass of glands which in all probability do secrete an outer membrane similar to that in the higher Decapoda. The presence of an inner, chitinous membrane secreted by the oviduct remains to be determined in these animals. But in view of the fact that two secreted membranes exist in Branchiopoda, e.g. Chirocephalus (Mawson \& Yonge, 1938) and in Copepoda (Häcker, I90I; Ziegelmayer, 1926) as well as in Decapoda it is not improbable that the characteristic properties of this cuticular (i.e. protein) substance are widely employed to protect the expanding developing egg throughout the Crustacea. Chitin would certainly seem to be useless for this purpose. Indeed the difference between the two membranes is similar to the difference between the cuticular integument of the Annelida, which stretches as the animal grows, and the chitinous integument of the Arthropoda which has to be moulted to permit increase in size.

\section{SUMMARY}

Subjection to a variety of fluids confirms the presence of two non-living membranes round the developing eggs of Homarus. It also reveals that the outer membrane has the restricted permeability of cuticle and the inner membrane the free permeability of chitin.

The inner, chitinous membrane bursts when the egg contents swell; the outer membrane stretches, up to $50 \%$ above its initial diameter, when the internal osmotic pressure rises. It also has considerable elasticity.

These properties of the outer membrane enable it to withstand the pressure to which the developing eggs are subjected and also to stretch during the development of the embryo, hence they have, considerable biological significance. The inner, chitinous membrane, which does not stretch, is probably ruptured and absorbed during development.

\section{REFERENCES}

Bargmann, H. E., 1937. The reproductive system of Euphausia superba. Discovery Rep., Vol xiv, pp. 325-50.

HÄCKER, V., I90I. Ueber die Fortpflanzung der limnetischen Copepoden des Titisees. Ber. Naturf. Ges. Freiburg, Bd. xII, pp. I-33.

Mawson, M. L. \& Yonge, C. M., I938. The origin and nature of the egg membranes in Chirocephalus diaphanus. Quart. Fourn. Micr. Sci., Vol. 80, pp. 553-65.

YoNGE, C. M., I932. On the nature and permeability of chitin. I. The chitin lining of the foregut of decapod Crustacea and the function of the tegumental glands. Proc. Roy. Soc. Lond., Ser. B, Vol. cxi, pp. 298-329.

- 1936. On the nature and permeability of chitin. II. The permeability of the uncalcified chitin lining the foregut of Homarus. Proc. Roy. Soc. Lond., Ser. B, Vol. cxx, pp. I5-4I.

I937. The nature and significance of the membranes surrounding the developing eggs of Homarus vulgaris and other Decapoda. Proc. Zool. Soc. Lond., Ser. A, Vol. 107, pp. 499-517.

ZIEGELMAYER, W., I926. Untersuchungen zur Quellungsmechanismus von Eizellen. Zeit. f. Zellf. u. mikr. Anat., Bd. 4, pp. 73-124. 